Research Article

\title{
Assessment of treatment adherence among hypertensive patients in a coastal area of Karnataka, India
}

\author{
Sneha D. Mallya, Ashwini Kumar*, Asha Kamath, Avinash Shetty, Sravan K. Reddy T., \\ Surabhi Mishra
}

Department of Community Medicine, Kasturba Medical College, Manipal University, Manipal, India

Received: 16 June 2016

Accepted: 02 July 2016

*Correspondence:

Dr. Ashwini Kumar,

E-mail: ashwin.kumar@manipal.edu

Copyright: (c) the author(s), publisher and licensee Medip Academy. This is an open-access article distributed under the terms of the Creative Commons Attribution Non-Commercial License, which permits unrestricted non-commercial use, distribution, and reproduction in any medium, provided the original work is properly cited.

\section{ABSTRACT}

Background: Hypertension is the most prevalent non communicable disease. With the rising burden of hypertension, prevention of complications such as cardiovascular events or stroke resulting due to uncontrolled blood pressure is of paramount significance. Strict adherence to prescribed antihypertensive medications is the key to blood pressure control and prevention of its complications and mortality. Hence, the present study was conducted with the objective of assessing the medication adherence among hypertensive patients on treatment.

Methods: A community based cross sectional study was conducted among 200 hypertensive patients on treatment for at least a year.

Results: The study included 200 hypertensive patients on medication, 69\% of them being females. More than two third $(79.5 \%)$ were literate and $37 \%$ of study population were classified as under below poverty line. Most (39.5\%) of the patients were 60-69 years of age and 55\% of the patients were on treatment for over 5years. Majority (96\%) of the hypertensive subjects in the study population were having an adherence rate of $\geq 85 \%$. About $13 \%$ of the individuals had an interrupted treatment in the last one month. The most common reasons for missing the medications were being forgetful and not having any symptoms.

Conclusions: The adherence rate in the current study is high, this needs to be maintained and further optimised.

Keywords: Community based, Medication adherence, Hypertension

\section{INTRODUCTION}

Hypertension is a common important and major public health problem. Globally, of the 17 million deaths a year due to cardiovascular diseases, 9.4 million deaths occur due hypertension and its complications. The global prevalence of hypertension among adults aged 18 years. and above was $22 \%$ in 2014 . $^{1}$ According to a systematic review and meta-analysis, the overall prevalence of hypertension in India was estimated to be $29.8 \%$, showing a significant difference in rural and urban prevalence $(27.6 \%$ (23.2-32.0) vs $33.8 \%$ (29.7-37.8); $\mathrm{P}=0.05){ }^{2} \quad$ However, hypertension goes largely unrecognized in the community unless its complication supervenes. Developments in antihypertensive therapies have been associated with marked reduction in morbidity and mortality from hypertension but effectiveness of treatment for hypertension is reduced greatly due poor adherence to treatment advices. Therefore, adherence to antihypertensive medication is very important in preventing complications of hypertension and its related mortality. Often, multiple factors such as age, gender, socioeconomic status, number of pills and the side effects of medication are considered to have an influence on adherence to treatment despite the availability of effective medicines. ${ }^{3-7}$ Therefore, a study was conducted in field 
practice area to assess adherence and factors associated with adherence to antihypertensive medications.

\section{METHODS}

The present study was conducted in the field practice area of department of community medicine of a medical college in southern coastal Karnataka, India. The field practice area of the department covers approximately 40,000 population in 11 villages. Apart from the availability of public and plenty of private health care facilities, department of community medicine runs one urban health centre and four rural health centres providing free basic general health services.

All of these five centres located in the field practice area provide treatment of hypertension and free medications to patients availing services irrespective of socio economic status. In addition to, the study area offers excellent health infrastructure comprising of three medical colleges including two ayurveda colleges, a government district hospital, four public health outlets and about 200 private practitioners, in the vicinity. The average literacy rate of Udupi district as per census 2011 was 92.1\%. Infant mortality rate in the field practice area is 3.83 per 1000 live births and no maternal death since the last three years. These health indicators can be compared to that of developed countries. With this background, this study was planned to assess the treatment adherence to antihypertensive medication in this set up.

Ethical committee approval was obtained from institutional ethics committee, Kasturba Hospital before the initiation of the study (IEC273/2016). Through house to house visit, individuals aged 30 years and above diagnosed to have hypertension and on treatment for at least one year were included in the study.

Anticipating an adherence rate of $50.33 \%$, with a relative precision of $15 \%$ and a non-response rate of $10 \%$ for a 95\% confidence interval, the sample size was estimated using $\mathrm{n}=4 \mathrm{pq} / \mathrm{d}^{2}$, where $\mathrm{p}=$ adherence rate in the previous study, $q=1-p$, to be $195 .^{8}$ After obtaining the informed consent from the participants, data was collected using a pretested semi-structured questionnaire by medico-social workers and post graduates of the department. Details regarding socio-demographic characteristics, adherence to pharmacological management of hypertension, and the nature of treatment were collected from participants. Adherence was calculated using the formula, number of prescribed medication consumed X100 divided by the number of prescribed antihypertensive medication over the past one month. Based on the adherence rate, subjects were classified into the categories of $\geq 85 \%$ adherence and $<85 \%$ adherence. Socio-economic status was assessed using revised modified BG Prasad scale. Data was entered and analysed by SPSS version 15.0. Results were expressed as frequency and proportions. Statistical tests like chi square test and fischer's exact test were used to assess significance of categorical variables. A p-value
$<0.05$ was considered statistically significant. Multivariate analysis was not performed owing to the small number of participants with adherence $<85 \%$.

\section{RESULTS}

A total of 200 individuals aged 30 years and above were interviewed. The mean $( \pm \mathrm{SD})$ age of participants was 64.6 (11.07) years. As shown in Table 1, majority of the study participants 138 (69\%) were females. Most 112 (56\%) of the participants were educated up to secondary school level. Among the participants 121 (60.5\%) were homemakers, and 58 (29\%) belonged to upper middle class. Of the participants, $58.5 \%$ were having APL ration card and $37 \%$ possessed a BPL ration card.

Table 1: Socio-demographic characteristics of study participants $n=200$.

\begin{tabular}{|c|c|c|}
\hline Variables & Category & Frequency (\%) \\
\hline \multirow{4}{*}{ Age } & $<49$ & $21(10.5)$ \\
\hline & $50-59$ & $37(18.5)$ \\
\hline & $60-69$ & $79(39.5)$ \\
\hline & $\geq 70$ & $63(31.5)$ \\
\hline \multirow{2}{*}{ Gender } & Male & $62(31.0)$ \\
\hline & Female & $138(69.0)$ \\
\hline \multirow{4}{*}{$\begin{array}{l}\text { Educational } \\
\text { status }\end{array}$} & Illiterate & $41(20.5)$ \\
\hline & Primary & $26(13.0)$ \\
\hline & Secondary (5-12) & $112(56.0)$ \\
\hline & $\begin{array}{l}\text { Graduation and } \\
\text { above }\end{array}$ & $21(10.5)$ \\
\hline \multirow{5}{*}{ Occupation } & Unskilled & $6(3.0)$ \\
\hline & $\begin{array}{l}\text { Unemployed and } \\
\text { retired }\end{array}$ & $40(20.0)$ \\
\hline & Skilled & $25(12.5)$ \\
\hline & Housewife & $121(60.5)$ \\
\hline & $\begin{array}{l}\text { Professional and } \\
\text { white collar }\end{array}$ & $9(4.5)$ \\
\hline \multirow{5}{*}{$\begin{array}{l}\text { Socio- } \\
\text { economic } \\
\text { status* }\end{array}$} & Upper class & $45(22.5)$ \\
\hline & Upper middle class & $58(29.0)$ \\
\hline & Middle class & $43(21.5)$ \\
\hline & Lower middle class & $27(13.5)$ \\
\hline & Lower class & $12(6.0)$ \\
\hline \multirow{3}{*}{$\begin{array}{l}\text { Ration card } \\
\text { status }^{\$}\end{array}$} & BPL card holder & $74(37)$ \\
\hline & APL card holder & $117(58.5)$ \\
\hline & Doesn't have card & $12(6.0)$ \\
\hline
\end{tabular}

$*(n=185)$ Socio-economic status could not be assessed for 15 of the participants; ${ }^{\$} \mathrm{BPL}=$ Below poverty line, $\mathrm{APL}=\mathrm{Above}$ poverty line.

The median (inter quartile range) duration of hypertension was $6.0(3,12)$ years. About $92(46 \%)$ had at least one comorbid condition with diabetes mellitus being the predominant among 66 (33\%). A higher proportion of the participants $137(68.5 \%)$ were on tablet containing a single drug. Calcium channel blocker 83 $(41.5 \%)$ was the most common class of drug and 58 (29\%) were on combination therapy for the management 
of hypertension. Two third of the patients $(74.6 \%)$ were taking less than or equal to a single tablet per day. It was alarming to notice the level of control of blood pressure among the participants, as only $58.5 \%$ had it under control. Blood pressure was under control for only $62.1 \%$ of the 66 patients with diabetes mellitus.
Encouragingly, large proportions (96\%) of the study participants were having an adherence rate of $\geq 85 \%$. However, about $5 \%$ of the patients interrupted treatment in the last one year for one or more months while $13 \%$ interrupted the treatment for a day or more in the last one month.

Table 2: Background characteristics of participants and adherence status ( $N=\mathbf{2 0 0})$.

\begin{tabular}{|c|c|c|c|c|}
\hline Variable & Category & Adherence $\geq 85 \%$ & Adherence $<\mathbf{8 5 \%}$ & p-value \\
\hline \multirow{2}{*}{ Age } & $\leq 50$ years & $22(88.0)$ & $3(12.0)$ & \multirow{2}{*}{0.063} \\
\hline & $>50$ years & $170(97.1)$ & $5(2.9)$ & \\
\hline \multirow{2}{*}{ Gender } & Male & $60(96.8)$ & $2(3.2)$ & \multirow{2}{*}{1.00} \\
\hline & Female & $132(95.7)$ & $6(4.3)$ & \\
\hline \multirow{2}{*}{ Literacy } & Illiterate & $41(100.0)$ & $0(0)$ & \multirow{2}{*}{0.211} \\
\hline & Literate & $151(95.0)$ & $8(5.0)$ & \\
\hline \multirow{3}{*}{ Occupation } & Employed & $36(92.3)$ & $3(7.7)$ & \multirow{3}{*}{0.093} \\
\hline & Homemakers & $116(96.9)$ & $5(4.1)$ & \\
\hline & Unemployed & $40(100)$ & $0(0)$ & \\
\hline \multirow{3}{*}{ Socio economic status } & Upper & 43 (95.6) & $2(4.4)$ & \multirow{3}{*}{1.00} \\
\hline & Middle & $123(96.1)$ & $5(3.9)$ & \\
\hline & Lower & $12(100.0)$ & $0(0)$ & \\
\hline \multirow{2}{*}{ Duration of hypertension } & $1-5$ years & $86(95.6)$ & $4(0.4)$ & \multirow{2}{*}{1.00} \\
\hline & $>5$ years & $106(96.4)$ & $4(3.6)$ & \\
\hline
\end{tabular}

Table 3: Effect of treatment and other selected characteristics on adherence $(\mathrm{N}=\mathbf{2 0 0})$.

\begin{tabular}{|c|c|c|c|c|}
\hline Variable & Category & Adherence $\geq 85 \%$ & Adherence <85\% & p-value \\
\hline \multirow{2}{*}{ Presence of any chronic co-morbidity } & Yes & $88(95.7)$ & $4(4.3)$ & \multirow{2}{*}{1.00} \\
\hline & No & $104(96.3)$ & $4(3.7)$ & \\
\hline \multirow{2}{*}{ Family history of hypertension } & Yes & $98(92.5)$ & $8(7.5)$ & \multirow{2}{*}{$0.007 *$} \\
\hline & No & $94(100)$ & $0(0)$ & \\
\hline \multirow{2}{*}{ Awareness regarding complication } & Yes & $125(96.2)$ & $5(3.8)$ & \multirow{2}{*}{1.00} \\
\hline & No & $67(95.7)$ & $3(4.3)$ & \\
\hline \multirow{2}{*}{ Number of tablets \# } & $\leq 1$ & $142(96.6)$ & $5(3.4)$ & \multirow{2}{*}{1.00} \\
\hline & $>1$ & $49(98)$ & $1(2)$ & \\
\hline \multirow{2}{*}{ Frequency of medication \# } & OD & $166(97.1)$ & $5(2.9)$ & \multirow{2}{*}{1.00} \\
\hline & $\geq \mathrm{BD}$ & $26(100)$ & $0(0)$ & \\
\hline \multirow{2}{*}{ Control status } & Controlled & $113(96.6)$ & $4(3.4)$ & \multirow{2}{*}{0.721} \\
\hline & Uncontrolled & $79(95.2)$ & $4(4.8)$ & \\
\hline \multirow{2}{*}{ Tobacco chewing } & Yes & $37(100)$ & $0(0)$ & \multirow{2}{*}{0.356} \\
\hline & No & $155(95.1)$ & $8(4.9)$ & \\
\hline \multirow{2}{*}{ Alcohol } & Yes & $26(100)$ & $0(0)$ & \multirow{2}{*}{0.600} \\
\hline & No & $166(95.4)$ & $8(4.6)$ & \\
\hline \multirow{2}{*}{ Smoking } & Yes & $16(100)$ & $0(0)$ & \multirow{2}{*}{1.00} \\
\hline & No & $176(95.7)$ & $8(4.6)$ & \\
\hline
\end{tabular}

$\# \mathrm{n}=197$, Three participants had stopped taking medicines completely; *Statistically significant

Table 2, shows the association between background characteristics and adherence. Maximum number $(98.7 \%)$ of adherent participants belonged to the age category of 60-69 years. Though none of the background characteristics showed statistical significance with adherence, following observations were made: the proportion of participants aged $>50$ years with adherence rate of $\geq 85 \%$ was higher compared to age $\leq 50$ years. (97.1 vs. 88.0). Out of the eight participants with adherence $<85 \%$, six were females. All the participants with adherence $<85 \%$ were literate and belonged to either upper or middle socio economic class.

Table 3, shows the association between adherence and treatment and certain selected characteristics. Presence of any chronic co-morbidity was not significantly associated with adherence. Family history of hypertension was statistically significantly associated with adherence rate 
of $<85 \%(\mathrm{p}=0.007)$. Five out of eight participants with adherence $<85 \%$ were on one or less than one tablet per day. There was no significant difference between control status of blood pressure and adherence. Incidentally, none of the participants with adherence $<85 \%$ reported any personal habits such as smoking or alcohol consumption.
Table 4, shows the distribution of the adherence according to the various categories of antihypertensive drugs. Three out of eight patients had completely stopped taking any medication. Out of the five subjects on antihypertensive drugs, no discernible pattern could be recognized with respect to the two categories of adherence.

Table 4: Adherence to hypertension treatment in relation to different categories of drugs ( $\mathrm{N}=\mathbf{2 0 0})$.

\begin{tabular}{|c|c|c|c|c|}
\hline Variable & Category & Adherence $\geq \mathbf{8 5} \%$ & Adherence $<85 \%$ & p-value \\
\hline \multirow{2}{*}{ Calcium channel blockers } & Yes & $83(97.6)$ & $2(2.4)$ & \multirow{2}{*}{0.471} \\
\hline & No & $109(94.8)$ & $6(5.2)$ & \\
\hline \multirow{2}{*}{ ACEI } & Yes & $6(100)$ & $0(0)$ & \multirow{2}{*}{1.00} \\
\hline & No & $186(95.9)$ & $8(4.1)$ & \\
\hline \multirow{2}{*}{ ARB } & Yes & $30(96.8)$ & $1(3.2)$ & \multirow{2}{*}{1.00} \\
\hline & No & $162(95.9)$ & $7(4.1)$ & \\
\hline \multirow{2}{*}{ Diuretics } & Yes & $3(100)$ & $0(0)$ & \multirow{2}{*}{1.00} \\
\hline & No & $189(95.9)$ & $8(4.1)$ & \\
\hline \multirow{2}{*}{ Centrally acting } & Yes & $12(100)$ & $0(0)$ & \multirow{2}{*}{1.00} \\
\hline & No & $180(95.7)$ & $8(4.3)$ & \\
\hline \multirow{2}{*}{ Combination drugs } & Yes & $55(96.5)$ & $2(3.5)$ & \multirow{2}{*}{0.634} \\
\hline & No & $132(97.8)$ & $3(2.2)$ & \\
\hline
\end{tabular}

Table 5, shows the reasons for missing the medication. The most common reported reason for missing the medication by the patients were forgetfulness and being asymptomatic. Three of the patients had completely stopped taking medication and the reported reasons for the same were as follows: being asymptomatic, on doctor's advice and being uncomfortable while on antihypertensive medication.

Table 5: Reasons for missing medication ( $\mathrm{N}=\mathbf{2 6})$.

\begin{tabular}{|ll|}
\hline Reasons & Frequency (\%) \\
\hline Forgetfulness & $16(53.3)$ \\
\hline $\begin{array}{l}\text { Asymptomatic/BP was assumed } \\
\text { normal }\end{array}$ & $7(23.3)$ \\
\hline Medication out of stock & $6(20)$ \\
\hline Doctor advised to stop & $2(6.6)$ \\
\hline Being busy with work & $1(3.3)$ \\
\hline Change in residence & $1(3.3)$ \\
\hline
\end{tabular}

\section{DISCUSSION}

The present study showed that $96 \%$ of the hypertensive patients were having an adherence rate of $\geq 85 \%$. The reported adherence rate in Indian literature varies widely, ranging from $15.3 \%-82.2 \% .^{3,9-12}$ Studies conducted outside India too show an extensive variation in adherence rates from $57.6 \%-75 \% .^{13-17}$ These varying rates of adherence may be due to the different methods used for measuring adherence and cut-off used for classifying as adherent.

In a hospital based study by Hema $\mathrm{K}$ et al in Andhra Pradesh $(n=400)$, only $15.3 \%(n=61)$ of the participants were found to have high adherence to anti-hypertensive medication based on 8 point Morisky medication adherence scale. ${ }^{10}$ Another study by Kumarswamy RC et al in a teaching hospital of Karnataka showed that $74 \%$ of the participants were adherent to the antihypertensive medication. ${ }^{9}$ A community based study by Vekatachalam $J$ et al in rural population of Tamilnadu $(n=473)$, the overall medication adherence was $24.1 \% .^{11}$ A community based study by Rao CR et al in the same area as the present study, reported an adherence rate of $82.2 \%$ among the participants. ${ }^{12}$ A community based study done in Taiwan by Lin YP et al $(n=144)$ among the elderly, showed that adherence to antihypertensive medication was $57.6 \% .^{17}$ In another community based study in Bangladesh by Khanam MA et al, $73.8 \%$ of the participants were adherent to the medication. ${ }^{14}$ A hospital based study done by Ambaw AD et al in Northwest Ethiopia ( $n=384), 64.6 \%$ of the study participants were found to be adherent to their treatment. ${ }^{13}$

In the present study five out of eight patients who had adherence $<85 \%$ were aged $\leq 60$ yrs. In contrast, a study by Rao BB et al showed that adherence rate towards antihypertensive medication was better among patient above 60 years of age $(67.2 \%)$ and this was found to be statistically significant $(\mathrm{p}=0.02$, OR $(95 \% \mathrm{CI})=1.91$ $(1.08-3.40)) .^{3}$ In another study done at Mangalore in a tertiary care hospital by Kumar $\mathrm{N}$ et al, found that adherence was found to be good in the age group of $\leq 60$ but not statistically significant $(\mathrm{p}=0.520, \operatorname{UOR}(95 \% \mathrm{CI})=$ $0.8(0.4-1.6)){ }^{6}$ In contrast to the findings of the present study, Mazzaglia $\mathrm{G}$ et al, showed significant association between gender and adherence $(\mathrm{p}=<0.001$, OR $(95 \% \mathrm{CI})=$ $0.72(0.65-0.81)){ }^{4}$ Ahmad $\mathrm{S}$ et al also reported that good 
adherence was seen among males than among females but it was not statistically significant $(\mathrm{p}=0.314$, OR $(95 \% \mathrm{CI})=1.25(0.81-1.94))^{5}$

Results akin to the present study were reported by Nagarkar AM et al where in education was not a significant determinant of adherence $(\mathrm{p}=0.169$, OR $(95 \% \mathrm{CI})=0.555(0.240-1.285)){ }^{18}$ Another study by Alsolami $F$ et al reported that having non-formal education was significant predictor of non-perfect adherence, $(p=0.031$, OR $(95 \% \mathrm{CI})=2.3 \quad(1.82-5))$. The same study also showed that there was no significance between duration of hypertension and adherence $(\mathrm{p}=0.907$, OR $(95 \% \mathrm{CI})=1.04(0.55-1.94)) .{ }^{19}$ Similar to the present study, a study by Lin YP et al, showed no association between adherence and being employed $(\mathrm{p}=0.93) .{ }^{17}$ Statistical significance was found between adherence and occupation $(\mathrm{p}=0.001)$ in a study by Behnood RA et al in Iran which found that those who received academic training and had occupations as clerk or in military personnel had better adherence. ${ }^{20}$

In conformity to the results of the present study, study by Nagarkar AM et al ( $\mathrm{p}=0.74$, OR (95\% CI) 1.144 (0.5922.208) ) and Rao BB et al $(\mathrm{p}=0.55$, OR (95\% CI) 1.2 (2.19-0.66)) also showed no association between socioeconomic status and adherence. ${ }^{18,3}$ However, the study done by Ahmad $\mathrm{S}$ et al in Moradabad showed statistical significance between SES and adherence where in participants belonging to upper middle class had better adherence compared to the lower middle class $(\mathrm{p}=0.001$ OR $(95 \% \mathrm{CI})=2.55(1.61-4.05)) .^{5}$ The study by Mazzaglia $\mathrm{G}$ et al, showed that most of the documented cardiovascular risk factors (diabetes mellitus, dyslipidaemia, and obesity) had significant $(\mathrm{p}=0.001)$ associations with high adherence to antihypertensive medication. ${ }^{4}$ However, the study by Kumar $\mathrm{N}$ et al showed that presence of comorbid conditions and adherence status were not significantly associated $(\mathrm{p}=0.14, \operatorname{UOR}(95 \% \mathrm{CI})=0.6(0.3-1.2)) .^{6}$ Interestingly, in the present study having family history was associated with adherence rate of $<85 \%$. In contrast to the present study, the study by Ahmad S showed that significance was found between family history and adherence $(\mathrm{p}=0.008$, OR $(95 \% \mathrm{CI})=1.82(1.16-2.85))$ and having a positive family history of hypertension was associated with good adherence. ${ }^{5}$ However, no significance was found between positive family history and adherence in a study by Kumar $\mathrm{N}$ et al $(\mathrm{p}=0.605$, OR $(95 \% \mathrm{CI})=0.8(0.4-$ 1.8)). ${ }^{6}$

As most of the study population were on one or less than one tablet a day, there was no significant association between number of drugs and adherence. Similar findings were reported from a study by Nagarkar AM et al in which there was no significance found between adherence and number of drugs taken $(\mathrm{p}=0.631, \mathrm{OR}(95 \%$ $\mathrm{CI})=0.714(0.255-1.998)) .{ }^{18}$ In contrast to the findings of the present study, Kumar $\mathrm{N}$ et al reported that there was a significance between adherence and number of drugs taken $(\mathrm{p}=0.03, \mathrm{OR}(95 \% \mathrm{CI})=0.4(0.2-0.9)) .{ }^{6}$ A study by Nagarkar AM et al showed that adherence and frequency of medication were not significantly associated $(\mathrm{p}=0.358$, OR $\quad(95 \% \quad \mathrm{CI})=0.390 \quad(0.084-1.807)) \quad$ which is in conformity to the results of the present study. ${ }^{18}$ However, Ahmad S reported that statistical significance was found between adherence and frequency of medication and those taking once a day medication were found to be better adherent $(\mathrm{p}=0.003$ OR $(95 \% \mathrm{CI})=1.96(1.25-3.08)){ }^{5}$ Similar to the present study, a study by Moise $\mathrm{N}$ et al showed that drug class was not associated with medication adherence $(\mathrm{P}=0.71) .^{21}$ Unlike present study, the study by Ahmad $\mathrm{S}$ showed that good adherence was present among those who had their blood pressure under control $(\mathrm{p}<0.001$, OR $(95 \% \quad \mathrm{CI})=4.35 \quad(2.61-7.24)) .^{5}$ Another study by Ambaw AD in northwest Ethiopia also showed that those who have controlled HTN had a significantly higher chance of being adherent to their treatment $(\mathrm{AOR}=2.93,95 \% \mathrm{CI}(1.73,4.96)) .{ }^{13}$

\section{CONCLUSION}

The study concludes with observation of very high adherence rate across socio demographic characteristics such as age, gender, education, occupation and socioeconomic status. However hypertension being a chronic and dynamic disease, adherence to the medication needs to be maintained continuously and fully optimized. Therefore, the current study has the inherent limitation of analysing the treatment adherence at one point of time. There is a need for all health providers to incorporate a system to record the adherence to treatment and blood pressure control at every visit until the patient requires to be on treatment.

Funding: No funding sources Conflict of interest: None declared

Ethical approval: The study was approved by the Institutional Ethics Committee

\section{REFERENCES}

1. A global brief on hypertension Silent killer, global public health crisis. Available at $\mathrm{WHO} /$ DCO/WHD/ 2013.2.URL: http://www.who.int/ cardiovascular_diseases /publications /global_ brief_hypertension/en. Accessed on 13 March 2016.

2. Anchala R, Kannuri KN, Pant H, Khan H, Franco $\mathrm{OH}$, Angelantonio ED et al. Hypertension in India: a systematic review and meta-analysis of prevalence, awareness and control of hypertension. J Hypertens. 2014;32(6):1170-7.

3. Rao BB, Kabra PR, Sreedhar M. Factors associated with adherence to antihypertensive treatment among hypertensive persons in an urban slum area of Hyderabad. Indian J Basic Applied Med Res. 2014;4(1):471-7.

4. Mazzaglia G, Ambrosioni E, Alacqua M, Filippi A, Sessa E, Immordino $\mathrm{V}$ et al. Adherence to antihypertensive medications and cardiovascular 
morbidity among newly diagnosed hypertensive patients. Circulation. 2009;120(16):1598-605.

5. Ahmad S. Assessment of adherence to antihypertensive treatment among patients attending a health care facility in North India. Int $\mathrm{J}$ Res Med. 2015;4(1);117-24.

6. Kumar N, Unnikrishnan B, Thapar R, Mithra P, Kulkarni V, Holla R et al. Factors associated with adherence to antihypertensive treatment among patients attending a tertiary care hospital in Mangalore, South India. Int $\mathbf{J}$ Cur Res Rev. 2014;6(10):77-85.

7. Kretchy IA, Owusu DFT, Danguah SA, Asampong E. A psychosocial perspective of medication side effects, experiences, coping approaches and implications for adherence in hypertension management. Clin Hypertens. 2015;17(21):19.

8. Dennis T, Meera NK, Binny K, Sekar MS, Kishore G, Sasidharan S. Medication adherence and associated barriers in hypertension management in India. CVD Prev Control. 2011:6(1);9-13.

9. Kumaraswamy RC, Kauser MM, Jagadeesh MK, Kumar RU, Kumar SRV, Afreen A et al. Study of determinants of non-adherence to anti-hypertensive medications in essential hypertension at a teaching hospital in Southern India. Chrismed $\mathbf{J}$ Health. 2015;4(1):57-60.

10. Hema K, Padmalatha P. Adherence to medication among hypertensive patients attending a tertiary care hospital in Guntur, Andhra Pradesh. Indian J Basic Applied Med Res. 2014;4(1):451-6.

11. Venkatachalam J, Abrahm SB, Singh Z, Stalin P, Sathya GR. Determinants of patient's adherence to hypertension medications in a rural population of kancheepuram district in Tamil Nadu, South India. Indian J Community Med. 2015;40(1):33-7.

12. Rao CR, Kamath VG, Shetty A, Kamath A. Treatment compliance among patients with hypertension and type 2 diabetes mellitus in a coastal population of Southern India. Int $\mathrm{J}$ Prev Med. 2014;5(8):992-8.

13. Ambaw AD, Alemie GA, Yohannes SMW, Mengesha ZB. Adherence to antihypertensive treatment and associated factors among patients on follow up at university of Gondar Hospital, Northwest Ethiopia. BMC Public Health. 2012;12:282.
14. Khanam MA, Lindeboom W, Koehlmoos TLP, Alam DS, Niessen L, Milton AH. Hypertension: adherence to treatment in rural Bangladesh findings from a population-based study. Glob Health Action. 2014;7:25028.

15. Iloh GUP, Ofoedu JN, Njoku PU, Amadi AN, Godswill UEU. Medication adherence and blood pressure control amongst adults with primary hypertension attending a tertiary hospital primary care clinic in Eastern Nigeria. Afr J Prm Health Care Fam Med. 2013;5(1):446.

16. Tomaszewski M, White C, Patel P, Masca N, Damani R, Hepworth J. et al. High rates of nonadherence to antihypertensive treatment revealed by high-performance liquid chromatography-tandem mass spectrometry (HP LC-MS/MS) urine analysis. Heart. 2014;100(11):855-61.

17. Lin YP, Huang YH, Yang YC, Wu JS, Chang CJ, $\mathrm{Lu}$ FH. Adherence to antihypertensive medications among the elderly: a community-based survey in Tainan city, Southern Taiwan. Taiwan Geriatr Gerontol. 2007;2(3):176-89.

18. Nagarkar AM, Gadhave SA, Sharma I, Choure I, Morisky D. Factors influencing medication adherence among hypertensive patients in a tertiary care hospital, Pune, Maharashtra. National J Comm Med. 2013;4(4):559-63.

19. Alsolami F, Correa VI, Hou XY. Factors affecting antihypertensive medications adherence among hypertensive patients in Saudi Arabia. Am J Med Medicaal Sci. 2015;5(4):181-9.

20. Behnood RA, Rabbanifar O, Pourzargar P, Rai A, Saadat $Z$, Saadat $H$. et al. Adherence to antihypertensive medications in Iranian patients. Int J Hypertens. 2016;15(08):752.

21. Moise N, Schwartz J, Bring R, Shimbo D, Kronish IM. Antihypertensive drug class and adherence: an electronic monitoring study. Am J Hypertens. 2015;28(6):717-21.

Cite this article as: Mallya SD, Kumar A, Kamath A, Shetty A, Reddy SKT, Mishra S. Assessment of treatment adherence among hypertensive patients in a coastal area of Karnataka, India. Int J Community Med Public Health 2016;3:1998-2003. 